\title{
Metallomics
}

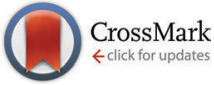

Cite this: Metallomics, 2014, 6,2242

Received 30th July 2014, Accepted 14th October 2014 DOI: $10.1039 / \mathrm{c} 4 \mathrm{mt} 00200 \mathrm{~h}$

www.rsc.org/metallomics

\section{An insight into silver nanoparticles bioavailability in rats}

\author{
Javier Jiménez-Lamana, ${ }^{\text {a }}$ Francisco Laborda, ${ }^{a}$ Eduardo Bolea, ${ }^{a}$ \\ Isabel Abad-Álvaro, ${ }^{a}$ Juan R. Castillo, ${ }^{a}$ Juliusz Bianga, ${ }^{\mathrm{b}}$ Man He, ${ }^{\mathrm{b}}$ Katarzyna Bierla, \\ Sandra Mounicou, ${ }^{b}$ Laurent Ouerdane, ${ }^{b}$ Sylvie Gaillet, ${ }^{c}$ Jean-Max Rouanet ${ }^{c}$ and \\ Joanna Szpunar
}

A comprehensive study of the bioavailability of orally administered silver nanoparticles (AgNPs) was carried out using a rat model. The silver uptake was monitored in liver and kidney tissues, as well as in urine and in feces. Significant accumulation of silver was found in both organs, the liver being the principal target of AgNPs. A significant ( $\sim 50 \%)$ fraction of silver was found in feces whereas the fraction excreted via urine was negligible $(<0.01 \%)$. Intact silver nanoparticles were found in feces by asymmetric flow field-flow fractionation (AsFIFFF) coupled with UV-Vis analysis. Laser ablation-ICP MS imaging showed that AgNPs were able to penetrate into the liver, in contrast to kidneys where they were retained in the cortex. Silver speciation analysis in cytosols from kidneys showed the metallothionein complex as the major species whereas in the liver the majority of silver was bound to high-molecular $(70-25 \mathrm{kDa})$ proteins. These findings demonstrate the presence of $\mathrm{Ag}(\mathrm{I})$, released by the oxidation of AgNPs in the biological environment.

\section{Introduction}

Due to their antimicrobial properties, silver nanoparticles (AgNPs) are used in many consumer and medical products. ${ }^{1}$ However, an increasing number of reports suggest that AgNPs may be potentially toxic ${ }^{2}$ which spurs research on the absorption, distribution, metabolism and excretion (ADME) behavior of metal-based nanomaterials in biological systems, recently referred to as "nanometallomics". 3

Several in vitro studies indicated that AgNPs are toxic to mammalian cells derived from the skin, ${ }^{4}$ liver,${ }^{5}$ lungs,${ }^{6}$ retina, ${ }^{7}$ nervous system ${ }^{8}$ and reproductive organs. ${ }^{9,10}$ On the other hand, in vivo studies, especially of the bioavailability upon oral exposure, are rather scarce. ${ }^{11} \mathrm{~A}$ study of the biodistribution of $60^{12}$ and $56 \mathrm{~nm}^{13}$ AgNPs in rats demonstrated a dosedependent accumulation of silver in the liver, lungs, kidney, stomach, testes and brain. ${ }^{12}$ A significant accumulation of small-size (22, 42 and $71 \mathrm{~nm}$ ) AgNPs in virtually all the abovementioned tissues was also observed in mice. ${ }^{14}$ However, silver was not detected in tissues from mice treated with large-sized

\footnotetext{
${ }^{a}$ Group of Analytical Spectroscopy and Sensors (GEAS), Institute of Environmental Sciences (IUCA), University of Zaragoza, Pedro Cerbuna 12, 50009 Zaragoza, Spain. E-mail: jjlamana@unizar.es; Fax: +34 976761292; Tel: +34 876553302 ${ }^{b}$ CNRS-UPPA, Laboratoire de Chimie Analytique Bio-inorganique et Environnement, UMR5254, Hélioparc, 2, Av. Angot, 64053 Pau, France

Equipe Nutrition et Métabolisme, UMR 204 NUTRIPASS, Prévention des Malnutritions et des Pathologies Associées CC 023, Université Montpellier Sud de France, Pl. Bataillon, 34095 Montpellier Cedex 05, France
}

(323 nm) AgNPs, proving that small-sized silver nanoparticles could be much easily absorbed in the gastrointestinal tract and translocated in the organs. Loeschner et al. ${ }^{15}$ showed that silver administered orally to rats in the form of AgNPs was less bioavailable than if administered as silver acetate. van der Zande et $a .^{16}$ found no differences in the tissue distribution pattern of two types of AgNPs in rats $(<20 \mathrm{~nm}$ uncoated and $<15$ nm PVP coated). All these studies were based on the total silver determination in bulk tissue samples by GF $\mathrm{AAS}^{12,13}$ or ICP $\mathrm{MS}^{14-16}$ upon microwave-assisted digestion.

A deeper insight into the location, transportation, and functional mechanism of AgNPs can be gained by the determination of the spatial distribution of AgNPs (or silver derived from them) in tissues and of the speciation - differentiation between the native and oxidized forms and the identification of the molecular targets and the related species. Laser ablation ICP MS imaging, largely developed by Becker et al., ${ }^{17-23}$ demonstrated an inhomogeneous distribution of many essential, toxic and probe metals in the heart, ${ }^{17}$ brain, ${ }^{18,21,23}$ kidneys $^{24}$ and other organ samples that, in many cases, could be correlated with the biological functions. In terms of speciation, asymmetric flow field-flow fractionation (AsFlFFF), typically applied to determine the size-distribution of engineered nanomaterials, ${ }^{25,26}$ offers potential to discriminate between the intact and metabolized NPs in complex matrices. ${ }^{27}$ Molecular targets of nanoparticles can be investigated by the plethora of hyphenated techniques ${ }^{28-30}$ as recently demonstrated for CdS nanoparticles. ${ }^{31}$

The aim of this work was to study the fate of orally administered AgNPs in rats by the determination of their 
accumulation in organs (kidney and liver) and their excretion (urine and feces) complemented by the tissue distribution imaging and speciation studies.

\section{Experimental}

\subsection{Instrumentation}

Total silver analysis. A CEM microwave digestion system, model MARSXpress, (CEM, Matthews, USA) equipped with XP1500 microwave vessels was used for the digestion of liver and kidney samples. Silver in tissues and urine samples was determined by using an ELAN DRC-e ICP MS (Perkin Elmer, Toronto, Canada). The sample introduction system consisted of a glass concentric slurry nebulizer and a cyclonic spray chamber (Glass Expansion, Melbourne, Australia) operated at manufacturer's recommended standard conditions. Feces were analysed by flame AAS using a Perkin-Elmer Model 2380 (Perkin Elmer) with an air: acetylene ( $40: 20$ ratio) flame.

Silver imaging. A NewWave UP-213 laser ablation (LA) system (NewWave Research, Freemont, USA) was coupled to an Agilent model 7500cs (Agilent, Tokyo, Japan) as described elsewhere, however, no hydrogen addition was necessary. ${ }^{32}$ The laser ablation system was operated in a focused spot mode at the repetition rate of $20 \mathrm{~Hz}$ with a spot size of $100 \mu \mathrm{m}$ and a scan speed of $100 \mu \mathrm{m} \mathrm{s}^{-1}$. The ablated matter was transported into the ICP with $\mathrm{He}$ gas $\left(500 \mathrm{~mL} \mathrm{~min}^{-1}\right)$ and mixed in a T-connector with aerosol obtained using a Micromist nebulizer and a double pass Scott spray chamber prior to ICP MS.

Asymmetric flow field-flow fractionation. An AF2000 system (Postnova Analytics, Landsberg, Germany) was used to identify silver nanoparticles in rat feces. Separation conditions were optimized as described elsewhere. ${ }^{33}$ The eluent was directed from the channel through a UV-Vis diode-array detector (Shimadzu, Duisburg, Germany) recording the signal between 200 and $650 \mathrm{~nm}$. The plasmon resonance of silver nanoparticles was used for their on-line detection by a UV-Vis detector. A complete spectrum was registered every $2 \mathrm{~s}$.

Size exclusion chromatography - ICP MS. A Superdex 75 10/ 300 GL column (GE Healthcare, Pittsburgh, USA) was coupled to an Agilent model 7500 (Agilent). Chromatographic separations were performed by using a model 1200 series HPLC pump (Agilent) as a delivery system. The exit of the column was connected directly to the nebulizer of the ICP MS equipped with a collision/reaction cell as described elsewhere. ${ }^{31}$

\subsection{Samples, reagents and materials}

Silver nanoparticles. Collargol, CAS registry number 9007$35-6$, available as powder and consisting of silver nanoparticles with an average diameter $c a .15 \mathrm{~nm}$ (with total silver content $\sim 70 \%$ ) in a protein matrix ( $\sim 30 \%)$ (Fig. 1) was obtained from Laboratorios Argenol S.L. (Zaragoza, Spain). Collargol is described in pharmacopeias as a strong antiseptic.

Standards. A commercially available metallothionein (MT-2) isolated from rabbit liver (Enzo Life Sciences, Farmingdale, USA) was used. It was provided by the manufacturer as a

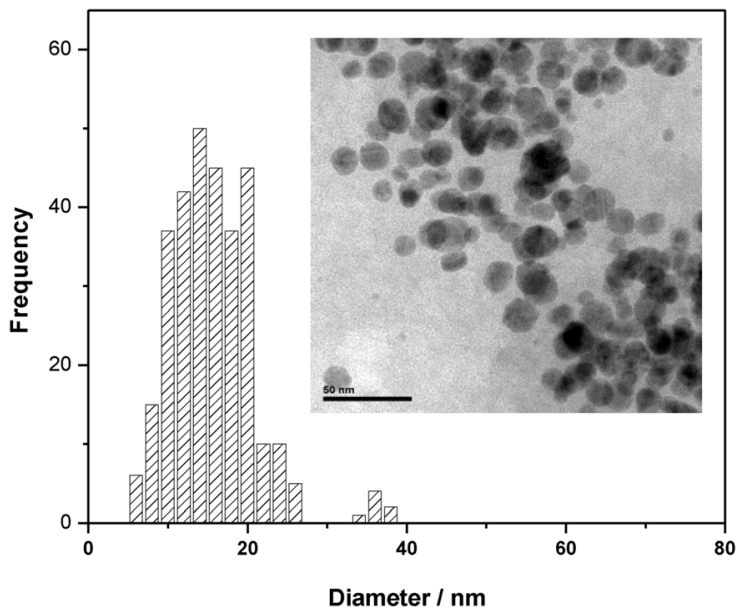

Fig. 1 Size distribution of Collargol obtained from transmission electron microscope images. Scale bar: $50 \mathrm{~nm}$.

solution in $25 \mathrm{mM}$ Tris/ $\mathrm{HCl}$ and $50 \mathrm{mM} \mathrm{NaCl}$ at $\mathrm{pH} 8$, with a concentration of $780 \mu \mathrm{g} \mathrm{mL}{ }^{-1}$. Dogfish Liver Certified Reference Material DOLT-4 (National Research Council Canada, Ottawa, Canada) with a certified silver content of $0.93 \pm$ $0.07 \mathrm{mg} \mathrm{kg}^{-1}$ was used to check the accuracy of the total silver determination.

Reagents. Analytical reagent grade chemicals purchased from Sigma-Aldrich (St. Louis, USA) were used throughout unless otherwised stated. Ultrapure water (resistivity $>18 \mathrm{M} \Omega \mathrm{cm}^{-1}$ ) was obtained from a Milli-Q Advantage system (Millipore, Billerica, USA).

\subsection{Procedures}

Animals. Weanling male Sprague-Dawley rats (Rattus norvegicus) (Janvier, Le Genest-St-Isle, France) weighing $92 \pm 3 \mathrm{~g}$ were randomly separated into three groups (A, B, C). Group A consisted of 24 rats randomly separated into two subgroups of twelve animals each: each subgroup consisted of 6 control rats and 6 experimental rats treated with Collargol for 30 and 45 days, respectively. Group B consisted of 12 rats: 6 control rats and 6 experimental rats treated with Collargol for 30 days, followed by just tap water for 30 days. Group C consisted of a group of 32 rats: 16 control rats and 16 experimental rats treated with Collargol for 81 days. All groups of rats were maintained in plastic cages in a temperature-controlled environment $\left(21 \pm 1{ }^{\circ} \mathrm{C}\right)$ with a relative humidity $60 \pm 4 \%$, and subjected to a $12 \mathrm{~h}$ light/dark cycle from $7 \mathrm{pm}$ to $7 \mathrm{am}$ and allowed free access to both food and water.

Rats were handled in compliance with European Union rules and according to the guidelines of $\mathrm{NIH}^{34}$ and the Committee on Animal Care at the University of Montpellier (France).

Diets and feeding procedures. Rats were fed on a standard diet supplied by SSNIFF (Spezialdiäten GmbH, Soest, Germany). Vitamins and mineral mixes were formulated according to AIN-93 guidelines. ${ }^{35}$ Rats and uneaten food were weighed daily. Rats in the first two groups (A and B) received daily by gavage either tap water (control group) or an aqueous solution of Collargol (experimental group) at a dose of $500 \mathrm{mg} \mathrm{kg}^{-1}$ body weight (BW) and 
those in the third group (C) at a dose of $820 \mathrm{mg} \mathrm{kg}^{-1} \mathrm{BW}$. Collargol powder was dissolved in ultra-pure water and sonicated for $60 \mathrm{~s}$. The volume of the suspensions fed was daily adjusted to the weight of rats. At the end of each experimental period, rats were deprived of food overnight.

Sample collection. For each animal and for each experimental period, the liver and the kidney were excised, weighed, sectioned for analyses and stored at $-80{ }^{\circ} \mathrm{C}$. For each animal and for each $30 \mathrm{~d}$ period, urine and feces were collected, pooled and frozen each day during the 7 last days, i.e. once the animals were adapted to the treatment.

Acid digestion of rat organs and feces. Lyophilized liver and kidney samples were ground manually to a particle diameter below $1 \mathrm{~mm}$. A ground sample (100-200 mg) was weighed accurately $( \pm 0.1 \mathrm{mg})$ in a microwave digestion vessel. $7 \mathrm{~mL}$ of conc. $\mathrm{HNO}_{3}$ and $3 \mathrm{~mL}$ of conc. $\mathrm{HCl}$ were added and the digestion was performed at $200{ }^{\circ} \mathrm{C}$ and 800 psi for $30 \mathrm{~min}$. In order to avoid the formation of insoluble $\mathrm{AgCl}$ the digestion was performed in the presence of excess of chloride to stabilize silver as the $\mathrm{AgCl}_{4}{ }^{3-}$ complex. After digestion the volume was made up to $50 \mathrm{~mL}$ with $3 \%(\mathrm{v} / \mathrm{v}) \mathrm{HCl}$. Feces samples were ground using grinding apparatus and a tank ball to a particle diameter below $1 \mathrm{~mm}$. A $100 \mathrm{mg}$ ground sample was weighed $( \pm 0.1 \mathrm{mg})$ in a vessel. $1 \mathrm{~mL}$ of conc. $\mathrm{HNO}_{3}$ and $3 \mathrm{~mL}$ of conc. $\mathrm{HCl}$ were added. Samples were digested in a sand bath and allowed to evaporate near to dryness. The remaining solid was dissolved in $1.5 \mathrm{~mL}$ of conc. $\mathrm{HCl}$ and the solution was made up to $15 \mathrm{~mL}$ with $10 \%(\mathrm{v} / \mathrm{v}) \mathrm{HCl}$ in a conical tube. The solutions were sonicated and centrifuged at $21^{\circ} \mathrm{C}$ for $10 \mathrm{~min}$ at $3000 \mathrm{rpm}$. A white precipitate was often observed at the bottom of the tube. The supernatant was removed and the solid was dissolved in $1.5 \mathrm{~mL}$ of conc. $\mathrm{HCl}$. Both volumes were combined and made up to $50 \mathrm{~mL}$ with $10 \%(\mathrm{v} / \mathrm{v}) \mathrm{HCl}$. Digestions were made in duplicate.

Laser ablation-ICP MS imaging. Kidney and liver samples were dissected and embedded in Tissue-Tek ${ }^{\circledR}$ OCT (Sakura, Alphen aan den Rijn, The Netherlands), frozen in liquid nitrogen, and stored at $-80{ }^{\circ} \mathrm{C}$. Sections were cut into $35 \mu \mathrm{m}$ thick slices using a Leica CM1950 cryostat (Leica Biosystems, Nussloch, Germany). The cryosections were directly mounted onto glass slides. The tissue section was systematically scanned (line by line) by a focused laser beam. The silver concentration heat map was constructed using Matlab software (Mathworks, Natick, USA).
Solubilization of feces prior to AsFlFFF. A $100 \mathrm{mg}$ ground sample was accurately weighed $( \pm 0.1 \mathrm{mg})$ in a conical tube. $2 \mathrm{~mL}$ of tetramethylammonium hydroxide (TMAH) $25 \%(\mathrm{w} / \mathrm{w})$ and $400 \mu \mathrm{L}$ of cysteine $0.5 \%(\mathrm{w} / \mathrm{w})$ were added and mixed in a tumbler for $24 \mathrm{~h}$ at $28 \mathrm{rpm}$. The solution was made up to $10 \mathrm{~mL}$ with a solution of $0.1 \%$ cysteine and $0.05 \%(\mathrm{w} / \mathrm{w})$ Triton $\mathrm{X}-100$, sonicated for $1 \mathrm{~min}$ and centrifuged at $21{ }^{\circ} \mathrm{C}$ for $15 \mathrm{~min}$ at 3000 rpm before analysis. Solubilizations were made by duplicate.

Size exclusion chromatography - ICP MS analysis. A $0.7 \mathrm{~g}$ sample (kidney or liver) was ground in liquid nitrogen. A volume of $2 \mathrm{~mL}$ of $200 \mathrm{mM}$ ammonium acetate ( $\mathrm{pH}$ 7.5) containing $1 \mathrm{mM}$ dithiothreitol (DTT) and $0.1 \mathrm{mM}$ phenylmethylsulfonylfluoride (PMSF) was added and the solution was sonicated for $1.5 \mathrm{~min}$ (power 25\%, $3 \mathrm{~s}$ stop, $5 \mathrm{~s}$ pulse). The mixture was centrifuged at $4{ }^{\circ} \mathrm{C}$ for $20 \mathrm{~min}$ at $120000 \mathrm{~g}$; the supernatant was collected and freeze dried. Prior to analysis, it was dissolved in $200 \mu \mathrm{L}$ of water. An aliquot of $10 \mu \mathrm{L}$ was diluted with $95 \mu \mathrm{L}$ of water, injected into the column and eluted at $0.55 \mathrm{~mL} \mathrm{~min}{ }^{-1}$ with $100 \mathrm{mM}$ ammonium acetate buffer ( $\mathrm{pH}$ 7.5).

\section{Results and discussion}

\subsection{Total silver content of rat organs}

To study the distribution of silver in the different exposure groups, the total silver content of the liver and kidney was determined as described above. The analytical performance of the method was tested in terms of recovery, accuracy and quantification limit. Recoveries (tested for $50 \mu \mathrm{g}$ of $\mathrm{Ag}$ ) ranged from 92-107\%. Accuracy was verified by analyzing a certified reference material, DOLT- 4 . The result obtained $\left(0.916 \pm 0.027 \mu \mathrm{g} \mathrm{g}^{-1}\right)$ was in good agreement with the certified value $\left(0.93 \pm 0.07 \mu \mathrm{g} \mathrm{g}^{-1}\right)$. Instrumental quantification limit, calculated as 10 times the standard deviation of instrumental blank $(n=10)$ divided by the sensitivity, was $0.007 \mu \mathrm{g} \mathrm{g}^{-1}$. The method quantification limit, calculated as 10 times the standard deviation of method blank $(n=10)$ divided by the sensitivity, was $0.012 \mu \mathrm{g} \mathrm{g}^{-1}$.

The silver contents of the liver and kidney were determined for control and experimental rats after $45 \mathrm{~d}$ exposure (group A). The results showed a significant accumulation of silver in both organs from the experimental group, well above the silver content found in the liver and kidney from the control group (Table 1). These results identify the liver and kidney as two target organs for orally administered AgNPs in rats.

Table 1 Silver content $\left(\mu \mathrm{g} \mathrm{g}^{-1}\right.$ ) of the lyophilized kidney and liver from control (T) and AgNP fed (C) rats after $45 \mathrm{~d}$ exposure. Average \pm standard deviation $(n=6)$

\begin{tabular}{|c|c|c|c|c|c|}
\hline Rat & Liver & Kidney & Rat & Liver & Kidney \\
\hline $\mathrm{T} 2$ & $0.077 \pm 0.002$ & $0.060 \pm 0.002$ & $\mathrm{C} 2$ & $1.903 \pm 0.069$ & $1.344 \pm 0.050$ \\
\hline T3 & $1.493 \pm 0.041$ & $0.235 \pm 0.032$ & $\mathrm{C} 3$ & $3.315 \pm 0.059$ & $1.336 \pm 0.031$ \\
\hline T5 & & $0.266 \pm 0.006$ & C5 & $1.487 \pm 0.026$ & $1.608 \pm 0.065$ \\
\hline T6 & & $0.029 \pm 0.002$ & C6 & $4.004 \pm 0.059$ & $4.714 \pm 0.085$ \\
\hline Control & $0.638 \pm 0.696$ & $0.109 \pm 0.111$ & AgNPs fed & $3.488 \pm 1.581^{a}$ & $2.022 \pm 1.351^{a}$ \\
\hline
\end{tabular}

${ }^{a}$ Significantly different from the control group, $P<0.05$. 
Table 2 Silver content ( $\mu \mathrm{g} \mathrm{g}^{-1}$ dry mass) of the liver and kidney from AgNPs fed rats after 30,45 and $81 \mathrm{~d}$ exposure. Average \pm standard deviation ( $n=6$ for 30 and 45 days; $n=14$ for 81 days)

\begin{tabular}{llll}
\hline & Days & \\
\cline { 2 - 4 } Organ & 30 & 45 & 81 \\
\hline Liver & $5.09 \pm 2.41$ & $3.49 \pm 1.59$ & $24.4 \pm 22.0$ \\
Kidney & $0.89 \pm 0.47$ & $2.02 \pm 1.35$ & $15.7 \pm 9.5$
\end{tabular}

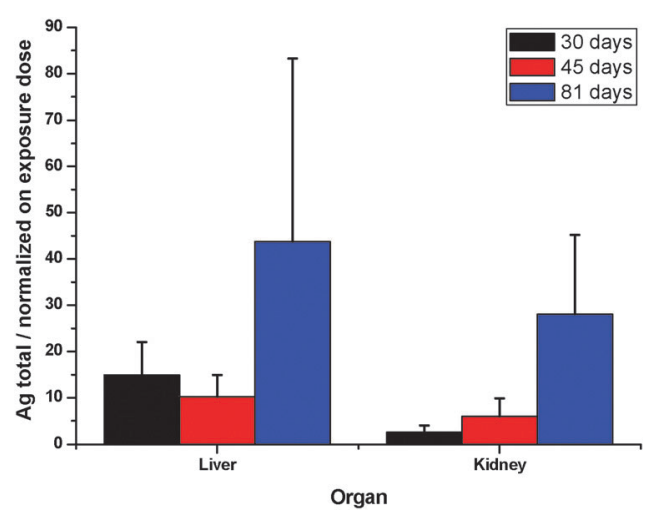

Fig. 2 Comparison of total silver content determined in the liver and kidney between different exposure groups. The results are normalized for the silver exposure dose and presented as the ratio between the silver content determined in each organ ( $\mu \mathrm{g} \mathrm{Ag}$ per $\mathrm{kg}$ organ) and the daily Collargol dose (mg Ag per kg body weight).

The higher content observed in liver could be explained by the higher presence of sulfur in this organ and the consequent formation of silver-thiol complexes. ${ }^{36}$ Despite the significant accumulation of silver in both organs, no toxic effects were observed in rats after $45 \mathrm{~d}$ exposure. Rats after $81 \mathrm{~d}$ exposure were reported elsewhere to show signs of oxidative stress and inflammation suggesting a long-term effect. ${ }^{37}$ In order to check this hypothesis, the total silver content in the liver and kidney from experiments at 30, 45 (group A) and 81 days (group C) was determined and compared. The results obtained (Table 2) showed that the total amount of silver in the liver and kidney increased significantly after $81 \mathrm{~d}$ exposure, which could explain the toxic effects found by Ebabe et $a l .{ }^{37}$ Moreover, in the same study the liver was reported as a target organ, which correlates with the high amount of silver found in the liver after $81 \mathrm{~d}$ exposure. However, the high silver content after $81 \mathrm{~d}$ exposure could be a consequence of not only the feeding time but also of the amount of silver administered to rats daily, as the Collargol dose for $81 \mathrm{~d}$ exposure was higher than for 30 and $45 \mathrm{~d}$ exposure. Therefore, the results here were normalized for the Collargol exposure dose defined as the ratio between the silver content determined in each organ ( $\mu \mathrm{g}$ silver per $\mathrm{kg}$ organ) and the daily Collargol dose (mg silver per $\mathrm{kg}$ body weight) (Fig. 2) showing that the long-term accumulation is produced regardless of the exposure dose.

\subsection{Total silver content of feces and urine}

Concerning the silver excretion, it can be supposed that silver is excreted in feces. Indeed Kim et al. ${ }^{13}$ showed that silver is
Table 3 Silver content of rat feces and urine from AgNPs fed rats after 30 and $30+30 \mathrm{~d}$ exposure. Average \pm standard deviation $(n=6)$

\begin{tabular}{lll}
\hline & Days & \\
\cline { 2 - 3 } & 30 & $30+30$ \\
\hline Feces $/ \mathrm{g} \mathrm{kg}^{-1}$ & $16.13 \pm 1.33$ & $<0.01$ \\
Urine $/ \mu \mathrm{g} \mathrm{L}^{-1}$ & $40.88 \pm 4.11$ & $0.35 \pm 0.04$ \\
\hline
\end{tabular}

absorbed, distributed to liver through the portal vein and excreted into the bile. In a similar way it can be argued that the silver accumulated in kidneys is eliminated in urine.

To confirm these hypotheses, the total silver concentrations in feces and urine from rats after $30 \mathrm{~d}$ exposure (group A) were determined. Taking into account the high inter-animal variation found in some cases, feces and urine from the same rat were analyzed. The results showed a high amount of silver excreted in feces (at $\mathrm{g} \mathrm{kg}^{-1}$ level) whereas the excretion of silver in urine was low (at $\mu \mathrm{g} \mathrm{L}^{-1}$ level) (Table 3). A similar trend was reported by Loeschner et al. ${ }^{15}$

To study the elimination of silver, the total silver content in feces and urine from experimental rats of group B (rats treated with Collargol for 30 days and another 30 days with tap water only) was analyzed. The results showed an almost complete elimination of silver after $30 \mathrm{~d}$ post-exposure (Table 3). Silver found in urine was $0.8 \%$ of silver found after $30 \mathrm{~d}$ exposure, whereas in feces no silver $\left(<0.01 \mathrm{~g} \mathrm{~kg}^{-1}\right)$ was detected. Furthermore, the silver content of the liver was determined and compared with that in feces from the same experimental group B. The silver concentration found in the liver after $30+$ $30 \mathrm{~d}$ experiment $\left(0.05 \mu \mathrm{g} \mathrm{g}^{-1}\right)$ was well below the silver content found in the liver after $30 \mathrm{~d}$ exposure $\left(5.09 \mu \mathrm{g} \mathrm{g}^{-1}\right)$. This finding was in good agreement with the analysis obtained for feces, as in both cases no silver accumulation was found after exposure.

\subsection{Silver distribution in the liver and kidney}

The analysis of total silver showed the accumulation in the liver and kidney, and the analysis of urine and feces confirmed its elimination via the digestive tract. Besides, the different concentrations of silver found in the liver and in feces with regard to the kidney and in urine suggest a different behavior of silver in both organs. This different behaviour could be related to the different localization of silver in the tissues. Therefore, the distribution of silver in the liver and kidney was investigated by LA-ICP MS imaging.

The results obtained for the liver and kidney of control rats (45 d exposure) and experimental rats (30 and $45 \mathrm{~d}$ exposure (group A)) are shown in Fig. 3. The obtained images revealed that $\mathrm{Ag}$ in the kidney is mainly localized in the cortex, both for 30 or $45 \mathrm{~d}$ exposure. For liver, a homogeneous distribution was observed without distinct regularities, showing a random penetration of $\mathrm{Ag}$ into the organ. This was confirmed for rats after $81 \mathrm{~d}$ exposure (Fig. 3). Also, the fact that most of the silver is found in the renal artery indicates transportation of silver by blood to the detoxifying organ.

The reproducibility of the silver imaging was investigated by comparing different slices from the same organ and organs from different animals with the same exposure time. The results (Fig. 4) confirm the satisfactory reproducibility. 
Control

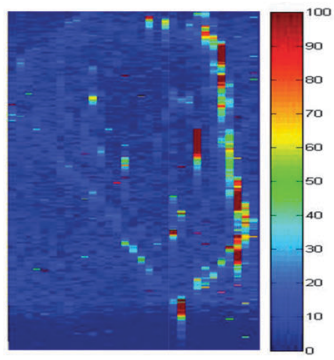

Liver

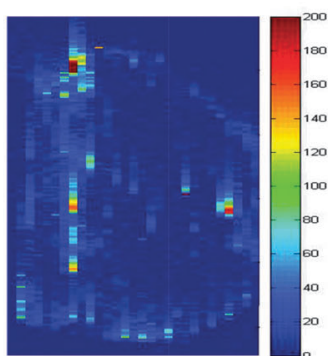

Kidney
30 days

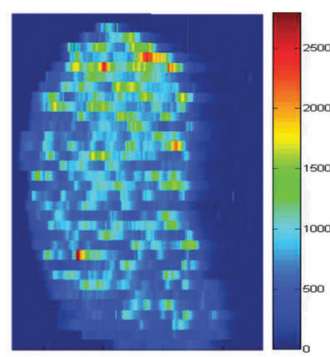

45 days

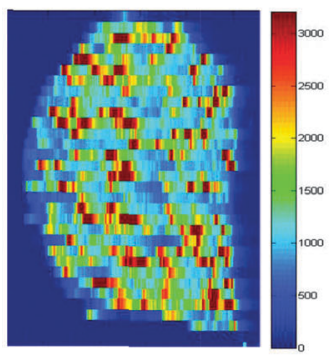

81 days

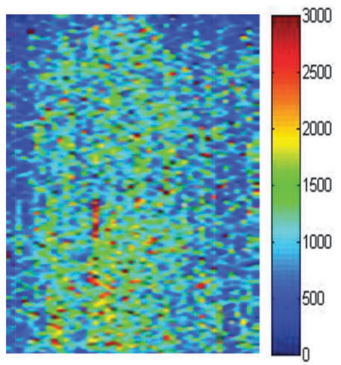

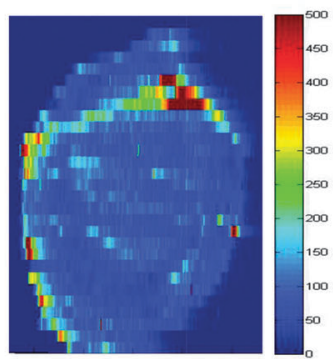
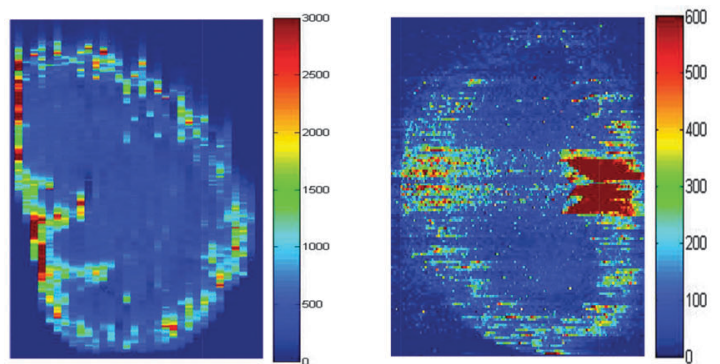

Fig. 3 Images of the rat liver and kidneys from control rats and AgNPs fed rats from 30, 45 and $81 \mathrm{~d}$ exposure. Scale bar: ${ }^{107} \mathrm{Ag}$ signal, cps.

(a)
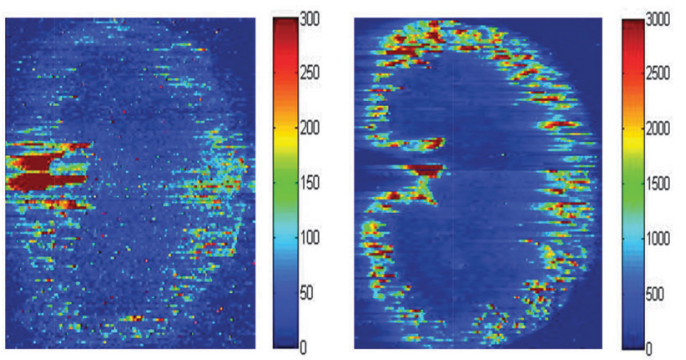

(b)
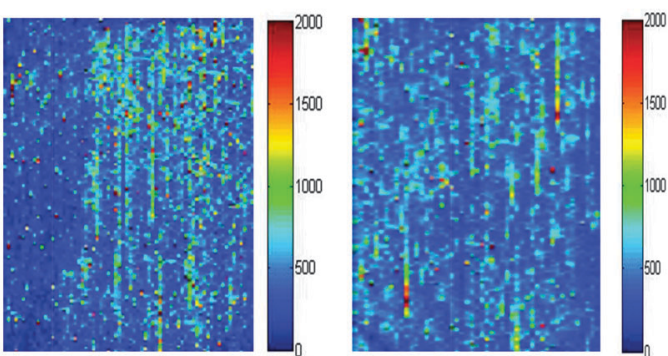

Fig. 4 Reproducibility of the LA-ICP MS analysis. (a) Different kidney slices from the same kidney from $81 \mathrm{~d}$ exposure experiment. (b) Different liver slices from different livers from $81 \mathrm{~d}$ exposure experiment. Scale bar: ${ }^{107} \mathrm{Ag}$ signal, cps.

\subsection{Identification of silver nanoparticles in feces}

Once in the gastrointestinal system, AgNPs can behave in two different ways: (i) they could be absorbed as intact nanoparticles, and/or (ii) dissolved by oxidation releasing $\mathrm{Ag}(\mathrm{I})$. According to the literature, the first scenario can occur to some extent. ${ }^{15,16}$ van der Zande et al. ${ }^{16}$ detected intact AgNPs in the liver, spleen and lungs upon exposure to rats. Loeschner et al. ${ }^{15}$ also detected nanosized silver granules in the ileum of animals exposed to silver nanoparticles. Interestingly, in both studies nanoparticulate silver was also detected for animals exposed to $\operatorname{Ag}(\mathrm{I})$ salts. This indicates that a fraction of nanoparticles might be bioavailable. Besides, nanoparticles detected in tissues can be formed in vivo from Ag(I) and they are probably composed of silver salts. ${ }^{16}$

Neither the total silver measurements nor LA-ICP MS imaging can provide information on whether the silver is present as dissolved or particulate forms. Therefore, in order to identify the form of $\mathrm{Ag}$ in rat feces, a procedure using AsFlFFF was developed. Feces were solubilized with TMAH in order to avoid the use of strongly oxidizing $\mathrm{HNO}_{3}$. The use of TMAH was recently reported to preserve AgNPs in cells ${ }^{27}$ and tissues. $^{38}$

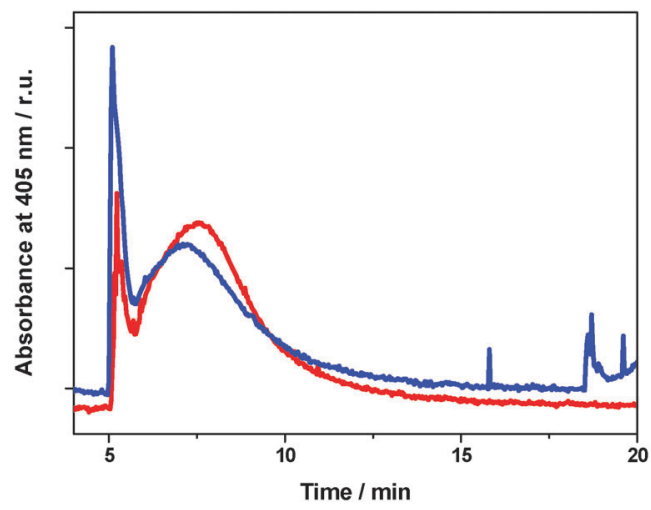

Fig. 5 Absorbance signals at $405 \mathrm{~nm}$ obtained for the solubilized feces (blue line), and a solution of Collargol in the solubilization media (red line). 
Fig. 5 shows the fractogram obtained for feces from rats after $30 \mathrm{~d}$ exposure (group A). It shows the presence of $\mathrm{Ag}$ nanoparticles with the size distribution resembling that of AgNPs in Collargol in the same medium which confirms the presence of intact AgNPs in the feces after the solubilization by TMAH.

\subsection{Insight into molecular targets of silver in the liver and kidney}

In order to get an insight into the speciation of silver accumulated in the liver and kidney, the relevant cytosols from 30, 45 (group A) and $81 \mathrm{~d}$ (group C) experiments were analyzed by SEC-ICP MS.

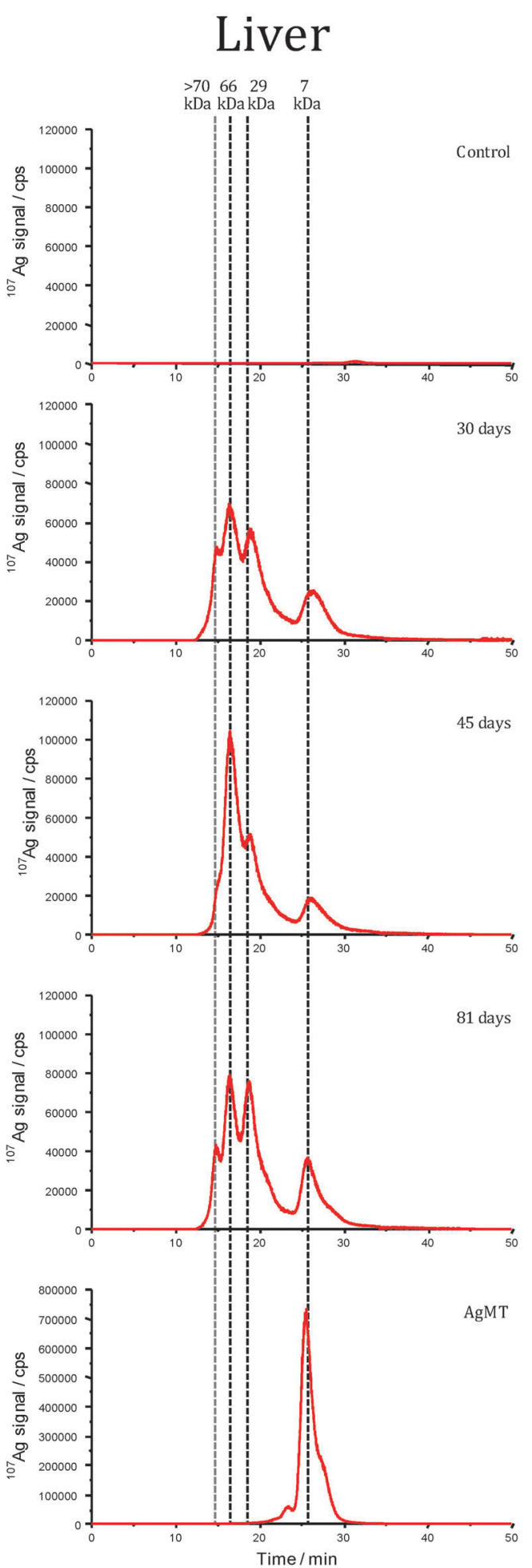

\section{Kidney}
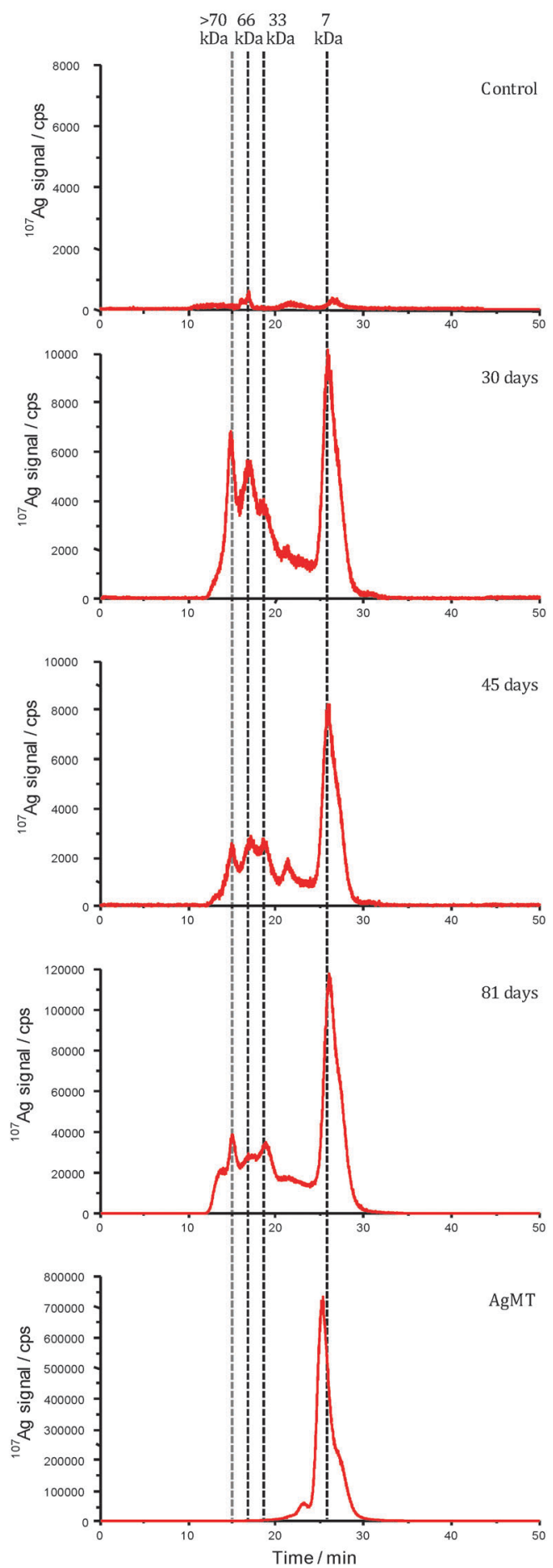

Fig. $6{ }^{107} \mathrm{Ag}$ signal obtained for cytosols extracted from the liver and kidney from experiments at 30, 45 and 81 days compared with the MT standard spiked with silver. 
Fig. 6 shows that silver is complexed by a number of biomolecules with standing out fractions at $>70,66,29$ and $7 \mathrm{kDa}$.

In the case of liver, the morphology of the chromatograms is practically independent of the exposure time and similar to that of sulphophilic elements such as $\mathrm{Cu}$ or $\mathrm{Cd}^{39}$ The overall intensity increases (as this is the case for the total $\mathrm{Ag}$ concentration). This suggests the existence of an abundant pool of proteins able to absorb the incoming silver by complexation once the MT pool is saturated. These are very likely to be cysteine-rich residues responsible for potent silver-binding capability. ${ }^{40}$

In the case of kidney, the ratio of the complexes with high molecular mass ligands $(>70-33 \mathrm{kDa})$ to those with low molecular weight ligands increases as a function of the exposure time. The low molecular weight fraction was identified by a comparison with the relevant standard as the complex of $\mathrm{Ag}$ with metallothionein. Kurasaki et $a{ }^{41}{ }^{41}$ reported an induction of Ag-induced metallothionein in kidneys by injecting silver lactate. The localization of Ag-MT in the kidney cortex was confirmed using autofluorescent signals and immunohistochemistry. ${ }^{41}$

These results confirm the presence of $\mathrm{Ag}$ in the form of complexes with biomolecules as a result of the oxidation of silver nanoparticles during digestion, as it has been confirmed by Liu et $a l^{42}$

\section{Conclusions}

An in vivo study based on oral administration of AgNPs to rats indicates a significant accumulation of silver in the kidney and liver, the latter being the principal target of AgNPs. The silver is relatively labile, being eliminated after 30 days. Silver is homogeneously distributed in the liver whereas in the kidney it is preferentially located in the cortex. Silver speciation demonstrated the oxidation of AgNPs in the biological environment producing $\operatorname{Ag}(\mathrm{I})$ complexed by a number of proteins, the major of which is metallothionein in the kidney. The presence of intact AgNPs in rat feces was detected for the first time.

\section{Authors contribution}

JJL, FL, EB, IAA and JRC carried out the total silver analysis of rat organs, feces and urine, as well as the asymmetric flow fieldflow fractionation-UV-Vis analysis. JB, MH, KB, SM, LO and JS carried out the Laser Ablation-ICP MS imaging analysis and the size exclusion chromatography-ICP MS analysis. SG and JMR performed the in vivo assays with rats.

\section{Acknowledgements}

Region Aquitaine, the Working Community of the Pyrenees (CTP-project 2010), the National Natural Science Foundation of China (No. 21075095) and the China Scholarship Council (File No. 2011842159) are acknowledged for their financial support. This work was supported by the Pyrenees Community Framework project CTPP06/10 and the Government of Aragon project CTPM1/12. The authors also thank Laboratorios Argenol S. L. for providing the Collargol samples. The authors would like to acknowledge the use of Servicio General de Apoyo a la Investigación - SAI, Universidad de Zaragoza. JB acknowledges the fellowship of the French Ministry of Education.

\section{References}

1 The Project on Emerging Nanotechnologies, http://www. nanotechproject.org/cpi/, accessed July 2014.

2 A. Nel, T. Xia, L. Mädler and N. Li, Science, 2006, 311, 622-627.

3 Y.-F. Li, Y. Gao, Z. Chai and C. Chen, Metallomics, 2014, 6, 220-232.

4 V. Rattanaruengsrikul, N. Pimpha and P. Supaphol, J. Appl. Polym. Sci., 2012, 124, 1668-1682.

5 K. Kawata, M. Osawa and S. Okabe, Environ. Sci. Technol., 2009, 43, 6046-6051.

6 C. Carlson, S. M. Hussain, A. M. Schrand, L. K. BraydichStolle, K. L. Hess, R. L. Jones and J. J. Schlager, J. Phys. Chem. B, 2008, 112, 13608-13619.

7 K. Kalishwaralal, E. Banumathi, S. Ram Kumar Pandian, V. Deepak, J. Muniyandi, S. H. Eom and S. Gurunathan, Colloids Surf., B, 2009, 73, 51-57.

8 J. Wang, M. F. Rahman, H. M. Duhart, G. D. Newport, T. A. Patterson, R. C. Murdock, S. M. Hussain, J. J. Schlager and S. F. Ali, Neurotoxicology, 2009, 30, 926-933.

9 L. Braydich-stolle, S. Hussain, J. J. Schlager and M. Hofmann, Toxicol. Sci., 2005, 88, 412-419.

10 N. Asare, C. Instanes, W. J. Sandberg, M. Refsnes, P. Schwarze, M. Kruszewski and G. Brunborg, Toxicology, 2012, 291, 65-72.

11 M. Ahamed, M. S. Alsalhi and M. K. J. Siddiqui, Clin. Chim. Acta., 2010, 411, 1841-1848.

12 Y. S. Kim, J. S. Kim, H. S. Cho, D. S. Rha, J. M. Kim, J. D. Park, B. S. Choi, R. Lim, H. K. Chang, Y. H. Chung, I. H. Kwon, J. Jeong, B. S. Han and I. J. Yu, Inhalation Toxicol., 2008, 20, 575-583.

13 Y. S. Kim, M. Y. Song, J. D. Park, K. S. Song, H. R. Ryu, Y. H. Chung, H. K. Chang, J. H. Lee, K. H. Oh, B. J. Kelman, I. K. Hwang and I. J. Yu, Part. Fibre Toxicol., 2010, 7, 20.

14 E. Park, E. Bae, J. Yi, Y. Kim, K. Choi, S. Hee, J. Yoon, B. Chun and K. Park, Environ. Toxicol. Pharmacol., 2010, 30, 162-168.

15 K. Loeschner, N. Hadrup, K. Qvortrup, A. Larsen, X. Gao, U. Vogel, A. Mortensen, H. R. Lam and E. H. Larsen, Part. Fibre Toxicol., 2011, 8, 18.

16 M. van der Zande, R. J. Vandebriel, E. Van Doren, E. Kramer, Z. Herrera Rivera, C. S. Serrano-Rojero, E. R. Gremmer, J. Mast, R. J. B. Peters, P. C. H. Hollman, P. J. M. Hendriksen, H. J. P. Marvin, A. A. C. M. Peijnenburg and H. Bouwmeester, ACS Nano, 2012, 6, 7427-7442.

17 J. S. Becker, U. Breuer, H. Hsieh, T. Osterholt, U. Kumtabtim, B. Wu, A. Matusch, J. A. Caruso and Z. Qin, Anal. Chem., 2010, 82, 9528-9533.

18 J. Dobrowolska, M. Dehnhardt, A. Matusch, M. Zoriy, N. Palomero-Gallagher, P. Koscielniak, K. Zilles and J. S. Becker, Talanta, 2008, 74, 717-723. 
19 J. S. Becker, R. C. Dietrich, A. Matusch, D. Pozebon and V. L. Dressler, Spectrochim. Acta, Part B, 2008, 63, 1248-1252.

20 H. Sela, Z. Karpas, M. Zoriy, C. Pickhardt and J. S. Becker, Int. J. Mass Spectrom., 2007, 261, 199-207.

21 J. S. Becker, J. Su. Becker, M. V. Zoriy, J. Dobrowolska and A. Matusch, Int. J. Mass Spectrom., 2007, 13, 1-6.

22 J. S. Becker, A. Matusch, C. Depboylu, J. Dobrowolska and M. V. Zoriy, Anal. Chem., 2007, 79, 6074-6080.

23 M. V. Zoriy, M. Dehnhardt, G. Reifenberger, K. Zilles and J. S. Becker, Int. J. Mass Spectrom., 2006, 257, 27-33.

24 M. Zoriy, A. Matusch, T. Spruss and J. S. Becker, Int. J. Mass Spectrom., 2007, 260, 102-106.

25 A. J. Bednar, A. R. Poda, D. M. Mitrano, A. J. Kennedy, E. P. Gray, J. F. Ranville, C. A. Hayes, F. H. Crocker and J. A. Steevens, Talanta, 2013, 104, 140-148.

26 M. Baalousha, B. Stolpe and J. R. Lead, J. Chromatogr. A, 2011, 1218, 4078-4103.

27 E. Bolea, J. Jiménez-Lamana, F. Laborda, I. Abad-Álvaro, C. Bladé, L. Arola and J. R. Castillo, Analyst, 2014, 139, 914-922.

28 S. Mounicou, J. Szpunar and R. Lobinski, Chem. Soc. Rev., 2009, 38, 1119-1138.

29 J. Szpunar, Analyst, 2000, 125, 963-988.

30 J. Szpunar, Analyst, 2005, 130, 442-465.

31 S. Mounicou, L. Ouerdane, B. L'Azou, I. Passagne, C. OhayonCourtès, J. Szpunar and R. Lobinski, Anal. Chem., 2010, 82, 6947-6957.
32 J. Bianga, G. Ballihaut, C. Pécheyran, Z. Touat, H. Preud'homme, S. Mounicou, L. Chavatte, R. Lobinski and J. Szpunar, J. Anal. At. Spectrom., 2012, 27, 25.

33 E. Bolea, J. Jiménez-Lamana, F. Laborda and J. R. Castillo, Anal. Bioanal. Chem., 2011, 401, 2723-2732.

34 National Research Council. Guide for the Care and the Use of Laboratory Animals, Publication no. 85-23 (rev.) National Institutes of Health, Bethesda, MD, 1985.

35 P. G. Reeves, F. H. Nielsen and G. C. Fahey, J. Nutr., 1993, 123, 1939-1951.

36 J. Liu, D. A. Sonshine, S. Shervani and R. H. Hurt, ACS Nano, 2010, 4, 6903-6913.

37 R. Ebabe Elle, S. Gaillet, J. Vidé, C. Romain, C. Lauret, N. Rugani, J. P. Cristol and J. M. Rouanet, Food Chem. Toxicol., 2013, 60, 297-301.

38 E. P. Gray, J. G. Coleman, A. J. Bednar, A. J. Kennedy, J. F. Ranville and C. P. Higgins, Environ. Sci. Technol., 2013, 47, 14315-14323.

39 M. Á. García-Sevillano, T. García-Barrera, F. Navarro-Roldán, Z. Montero-Lobato and J. L. Gómez-Ariza, J. Proteomics, 2014, 104, 66-79.

40 P. Coyle, J. C. Philcox, L. C. Carey and A. M. Rofe, Cell. Mol. Life Sci., 2002, 59, 627-647.

41 M. Kurasaki, M. Okabe, S. Saito, O. Yamanoshita, T. Hosokawa and T. Saito, J. Inorg. Biochem., 2000, 78, 275-281.

42 J. Liu, Z. Wang, F. D. Liu, A. B. Kane and R. H. Hurt, ACS Nano, 2012, 6, 9887-9899. 